\title{
Laser damage of Silica and Hafnia thin films made with different deposition technologies
}

\author{
Laurent Gallais, Jérémie Capoulade, Jean-Yves Natoli, Mireille Commandré, Michel \\ Cathelinaud, Cian Koc, Michel Lequime \\ Institut Fresnel (UMR CNRS 6133) - Université Paul Cezanne - Université de Provence - Ecole \\ Centrale Marseille \\ Domaine Universitaire de St Jérôme - 13397 Marseille Cedex 20 - France
}

\begin{abstract}
A comparative study is made on the laser damage resistance of monolayers coatings made with different technologies. $\mathrm{H} \mathrm{fO} 2$ and $\mathrm{SiO} 2$ thin films have been deposited on fused silica substrates with Dual Ion Beam Sputtering, Electron Beam Deposition (with and without Ion Assistance) and Reactive Low Voltage Ion Plating technologies. The laser damage thresholds of these coatings have been determined at $1064 \mathrm{~nm}$ and $355 \mathrm{~nm}$ using a nanosecond pulsed YAG laser, and a 1-on-1 test procedure.
\end{abstract}

\section{INTRODUCTION}

$\mathrm{HfO}_{2}$ and $\mathrm{SiO}_{2}$ are widely used materials for the production of laser damage resistant multilayer coatings. ${ }^{1-3}$ From numerous studies, it appears that e-beam-deposited $\mathrm{H} \mathrm{fO}_{2} / \mathrm{SiO}_{2}$ multilayer coatings shows higher damage threshold than the same coatings deposited with energetic deposition techniques. ${ }^{4-8}$ But these last techniques have better optical, mechanical and environmental properties. The improvement of the laser damage resistance of dense layers has therefore a considerable interest for the community. In this context we report in this paper the recent development made at the Fresnel Institute in the development of dense coatings for high power applications.

This paper is a summary of works published in reference ${ }^{9}$ for $\mathrm{SiO}_{2}$ and ${ }^{10}$ for $\mathrm{HfO}_{2}$. Then one should refer to these publications for more details.

\section{MATERIALS AND METHODS}

\subsection{Samples description}

The substrate choice and preparation (cleaning and polishing) is critical for the production of coatings for high power applications and it can ultimately limit the thresholds for a given coating. ${ }^{11,12}$ For this study, we used 1-inch diameter fused silica substrates polished for high power applications. Herasil was used for the silica coatings and Corning 7980 was used for hafnia coatings. For each coating material (either silica or hafnia) all the substrates (either Herasil or Corning 7980) were coming from the same batch and have been polished at the same time.

To clean these substrates we used an automatic aqueous cleaning procedure, involving ultrasonic immersion and detergents followed by de-ionized water rinsing and drying.

The aim of the study was to test samples at 355 and $1064 \mathrm{~nm}$. However, to have comparable results at a given wavelength, it is necessary to assure that the optical thickness of the different samples are the same, in order to have the same standing electric field in the coating. Then in the case of hafnia, a first serie of samples half wave at $1064 \mathrm{~nm}$ has been made for testing at $1064 \mathrm{~nm}$ and a second serie, half wave at $355 \mathrm{~nm}$, was made for $355 \mathrm{~nm}$ testing.

In the case of silica however the optical thickness of the layer is not a relevant parameter as regards the electric field distribution, because of the very low refractive index difference between the substrate and the layer. Then the same samples were used for 1064 and $355 \mathrm{~nm}$ tests.

Further author information: (Send correspondence to L. Gallais)

E-mail: laurent.gallais@fresnel.fr, Telephone: 33491288072

Laser-Induced Damage in Optical Materials: 2007, edited by G. J. Exarhos, A. H. Guenther, K. L. Lewis, D. Ristau,

M. J. Soileau, C. J. Stolz, Proc. of SPIE Vol. 6720, 67200S, (2007) · 0277-786X/07/\$18 · doi: 10.1117/12.752952

Proc. of SPIE Vol. 672067200 S-1 


\subsection{Deposition process}

The $\mathrm{SiO}_{2}$ coatings were deposited by the following techniques: Electron Beam Deposition, Ion Assisted Deposition, Reactive Low Voltage Ion Plating (RLVIP) and Dual Ion Beam Sputtering.

The hafnia samples were prepared by Electron Beam Deposition using either a Hafnium or Hafnia source (respectively the samples will be called EBD-Hf or $\mathrm{EBD}_{-} \mathrm{HfO}_{2}$ in the following text), Reactive Low Voltage Ion Plating and Dual Ion Beam Sputtering (DIBS).

The process parameters used to produce these coatings are reported in table 1 and 2 .

Table 1. Process parameters for $\mathrm{SiO}_{2}$ coatings

\begin{tabular}{ccccc}
\hline & \multicolumn{4}{c}{ Deposition technique } \\
\cline { 2 - 5 } Procedure & EBD & EBD-IAD & RLVIP & DIBS \\
\hline Starting material & Silicon $99.999 \%$ & Silica & Silicon $99.999 \%$ & Silicon \\
hline Base pressure & & $3 \times 10^{-7} \mathrm{mbar}$ & $7 \times 10^{-7} \mathrm{mbar}$ \\
\hline Chamber pressure & $9 \times 10^{-4} \mathrm{mbar}$ & $3 \times 10^{-4}$ & $9.5 \times 10^{-4} \mathrm{mbar}$ & $3 \times 10^{-4} \mathrm{mbar}$ \\
& $\left(\mathrm{O}_{2}\right)$ & $\left(\mathrm{O}_{2}\right)$ & $\left(\mathrm{Ar}+\mathrm{O}_{2}\right)$ & $\left(\mathrm{Ar}+\mathrm{O}_{2}\right)$ \\
\hline Deposition rate & $0.8 \mathrm{~nm} / \mathrm{s}$ & $0.4 \mathrm{~nm} / \mathrm{s}$ & $0.8 \mathrm{~nm} / \mathrm{s}$ & $0.1 \mathrm{~nm} / \mathrm{s}$ \\
\hline Substrate temperature & $250^{\circ} \mathrm{C}$ & $50^{\circ} \mathrm{C}$ & $150^{\circ} \mathrm{C}$ & $50^{\circ} \mathrm{C}$ \\
& no heater & no heater & no heater & no heater \\
\hline Anode voltage & \multicolumn{3}{c}{} \\
\hline
\end{tabular}

Table 2. Process parameters for $\mathrm{HfO}_{2}$ coatings

\begin{tabular}{|c|c|c|c|c|}
\hline \multirow[b]{2}{*}{ Procedure } & \multicolumn{4}{|c|}{ Deposition technique } \\
\hline & EBD-Hf & $\mathrm{EBD}-\mathrm{HfO}_{2}$ & RLVIP & $\overline{\text { DIBS }}$ \\
\hline \multirow[t]{3}{*}{ Starting material } & Hafnium $99.5 \%$ & $\mathrm{HfO}_{2}$ tablets & Hafnium $99.5 \%$ & Hafnium $99.4 \%$ \\
\hline & Umicore & Merck Patinal & Umicore & Neyco \\
\hline & granulate $1-10 \mathrm{~mm}$ & & granulate $1-10 \mathrm{~mm}$ & \\
\hline liner & carbon & molybdenium & carbon & \\
\hline evaporation gun & $10 \mathrm{kV}$ & $10 \mathrm{kV}$ & & $1 \mathrm{kV}, 400 \mathrm{~mA}$ \\
\hline & & & & acceleration : $350 \mathrm{~V}$ \\
\hline \multirow[t]{4}{*}{ Assistance parameters } & & & plasma source & Ion gun : \\
\hline & & & arc current and voltage : & $375 \mathrm{~V}, 350 \mathrm{~mA}$ \\
\hline & & & $55 \mathrm{~A}, 66 \mathrm{~V}$ & acceleration : $300 \mathrm{~V}$ \\
\hline & & & Anode voltage : $42 \mathrm{~V}$ & \\
\hline Base pressure & $3 \times 10^{-7} \mathrm{mbar}$ & $3 \times 10^{-7} \mathrm{mbar}$ & $3 \times 10^{-7}$ mbar & $7 \times 10^{-7}$ mbar \\
\hline \multirow[t]{2}{*}{ Chamber pressure } & $5 \times 10^{-4} \mathrm{mbar}$ & $5 \times 10^{-4} \mathrm{mbar}$ & $6 \times 10^{-4} \mathrm{mbar}$ & $5.5 \times 10^{-4} \mathrm{mbar}$ \\
\hline & $\left(\mathrm{O}_{2}\right)$ & $\left(\mathrm{O}_{2}\right)$ & $\left(\mathrm{Ar}+\mathrm{O}_{2}\right)$ & $\left(\mathrm{Ar}+\mathrm{O}_{2}\right)$ \\
\hline Deposition rate & $0.9 \mathrm{~nm} / \mathrm{s}$ & $0.9 \mathrm{~nm} / \mathrm{s}$ & $0.2 \mathrm{~nm} / \mathrm{s}$ & $0.05 \mathrm{~nm} / \mathrm{s}$ \\
\hline \multirow[t]{2}{*}{ Substrate temperature } & $250^{\circ} \mathrm{C}$ & $250^{\circ} \mathrm{C}$ & $200-250^{\circ} \mathrm{C}$ & $50^{\circ} \mathrm{C}$ \\
\hline & lamp heaters & lamp heater & no heater & no heater \\
\hline Anode voltage & & & $42 \mathrm{~V}$ & \\
\hline
\end{tabular}

\subsection{Laser damage tests}

The configuration used for LIDT measurement is described on figure 1. The laser source is an injected Nd:YAG laser (Quantel YG 980) with a pulse duration of $11 \mathrm{~ns}$ (effective pulse duration at $1 / \mathrm{e}^{13}$ ) and a maximum repetition rate of $10 \mathrm{~Hz}$. The laser can operate at $1064 \mathrm{~nm}$ or $355 \mathrm{~nm}$, with a maximum energy of $1.5 \mathrm{~J}$ at 1064 $\mathrm{nm}$ and $450 \mathrm{~mJ}$ at $355 \mathrm{~nm}$. It works at a repetition rate of $10 \mathrm{~Hz}$ to keep a good stability of energy and beam characteristics. A mechanical shutter permits to work in single shot mode. Energy of the beam is controlled with a variable attenuator (half wave plate and polarizer). 


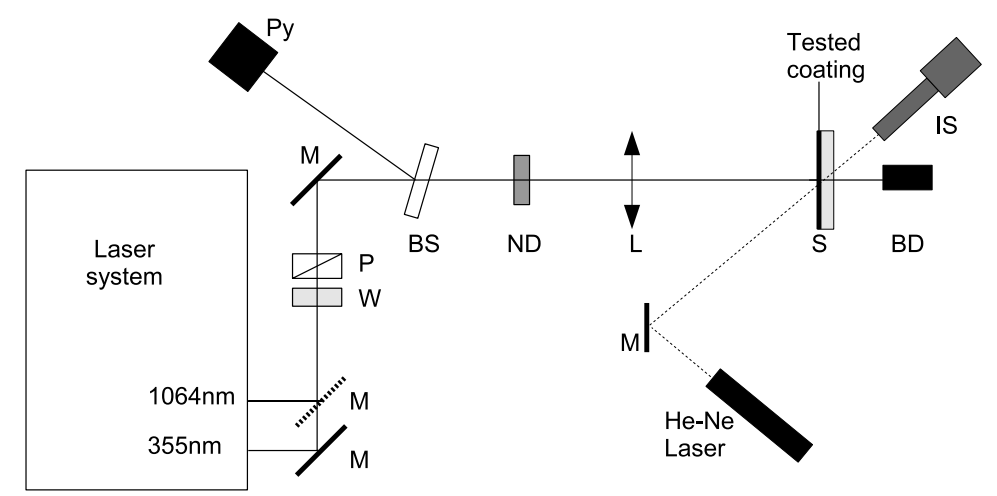

Figure 1. Experimental configuration for laser damage tests

The laser beam (linearly polarized and in normal incidence) is focused on the front face of the coated sample (see figure 1) with a plano-convex lens at $1064 \mathrm{~nm}(\mathrm{f}=35 \mathrm{~mm})$ and an objective in the case of $355 \mathrm{~nm}(\mathrm{f}=11.5 \mathrm{~mm})$. The spot size has been measured in the sample plane with a beam analyser : the spot diameter is $44 \mu m$ at $1064 \mathrm{~nm}$ and $3 \mu \mathrm{m}$ at $355 \mathrm{~nm}$ (diameter at $1 / \mathrm{e}$ ).

The damage detection is done by comparing the area before and after irradiation with an imaging system (magnification : X216) and an image processing software. The damage criterion is then any visible modification detected with this system.

For each shot, energy is measured with a pyroelectric detector and recorded. The fluence is then calculated according to the ISO standard by using the effective spot size. ${ }^{13}$

The LIDT measurement setup is fully automated, which allows to measure laser damage probabilties with a great number of points. In this study, the damage test procedure 1-on-1 is used : by counting the number of damaged regions at each fluence $\mathrm{F}$ we estimate and plot the damage probability curve $\mathrm{P}(\mathrm{F})$. To have a good accuracy of the measurement, each curve $\mathrm{P}(\mathrm{F})$ is plotted with 1000 data points that involve 20 different fluences and 50 tested regions at each fluence.

\section{RESULTS AND DISCUSSION}

The test results are plotted on figures $2(355 \mathrm{~nm})$ and $3(1064 \mathrm{~nm})$ for silica, and figures $4(355 \mathrm{~nm})$ and $5(1064 \mathrm{~nm})$ for hafnia. The plain lines curves on these figures are the fit of the experimental points, made with a statistical model relying of the hypothesis of defect initiation (see $\mathrm{ref}^{14}$ ). The shape and threshold of these curves are linked to the initiator characteristics (density, nature,...). However the analysis of these curves is not discussed in details in this paper since our study is more focused on the comparisons of the technologies.

One difficulty in laser damage testing is often to compare laser damage performances of a particular material between different testing facilities (large discrepancies are found between publications). Indeed the damage threshold can be linked to many factors such as the test procedure, the beam profile, the wavelength, the pulse profile and duration, the number of shots... For this reason we also give in the following sections the LIDT of the substrates (polished, cleaned and stocked with the coatings substrates) and tested in the same experimental conditions. 


\subsection{Silica}

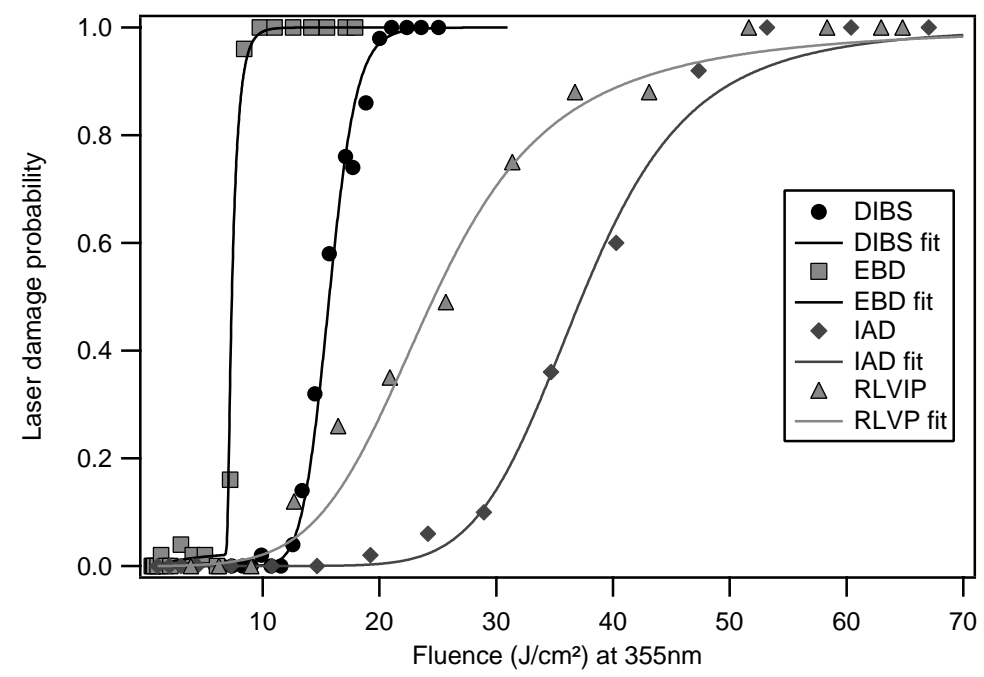

Figure 2. Laser damage probability curves measured at $355 \mathrm{~nm}$ for the different silica samples

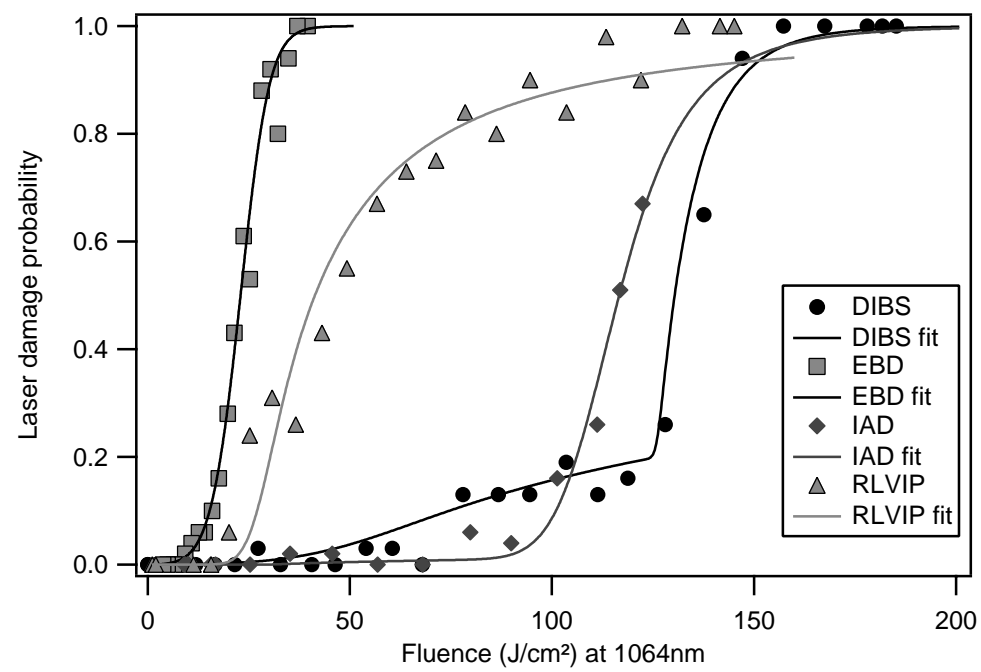

Figure 3. Laser damage probability curves measured at $1064 \mathrm{~nm}$ for the different silica samples

The LIDT of the films, i.e. highest fluence where no damage is observed, are the following :

- EBD : $4 \mathrm{~J} / \mathrm{cm}^{2}$ at $355 \mathrm{~nm}$ and $12 \mathrm{~J} / \mathrm{cm}^{2}$ at $1064 \mathrm{~nm}$

- EBD-IAD : $19 \mathrm{~J} / \mathrm{cm}^{2}$ at $355 \mathrm{~nm}$ and $30 \mathrm{~J} / \mathrm{cm}^{2}$ at $1064 \mathrm{~nm}$

- RLVIP : $10 \mathrm{~J} / \mathrm{cm}^{2}$ at $355 \mathrm{~nm}$ and $20 \mathrm{~J} / \mathrm{cm}^{2}$ at $1064 \mathrm{~nm}$

- DIBS : $9 \mathrm{~J} / \mathrm{cm}^{2}$ at $355 \mathrm{~nm}$ and $35 \mathrm{~J} / \mathrm{cm}^{2}$ at $1064 \mathrm{~nm}$

- Substrate : $30 \mathrm{~J} / \mathrm{cm}^{2}$ at $355 \mathrm{~nm}$ and $70 \mathrm{~J} / \mathrm{cm}^{2}$ at $1064 \mathrm{~nm}$

High laser damage threshold is often reported in the litterature for low density thin films, such as those obtained by Sol-Gel or Electron Beam Deposition. ${ }^{1,3,6,15}$ In our study however, we observe that the dense layers (obtained with ion-assisted process) exhibit a very good threshold in the infrared (DIBS) and the UV (IAD) 
compared with layers manufactured by classical EBD. This indicate that a good quality in terms of defects has been obtained for these dense layers. Finally, the Dual Ion Beam Sputtering technique appears to be a promising technique for the production of high laser damage threshold coatings, since it also leads to very good mechanical, structural and optical properties for the layers.

However it is know that it is relatively easy to obtain silica layers with a high LIDT, and that the high index material in a multilayer stack will be the limiting material.

\subsection{Hafnia}

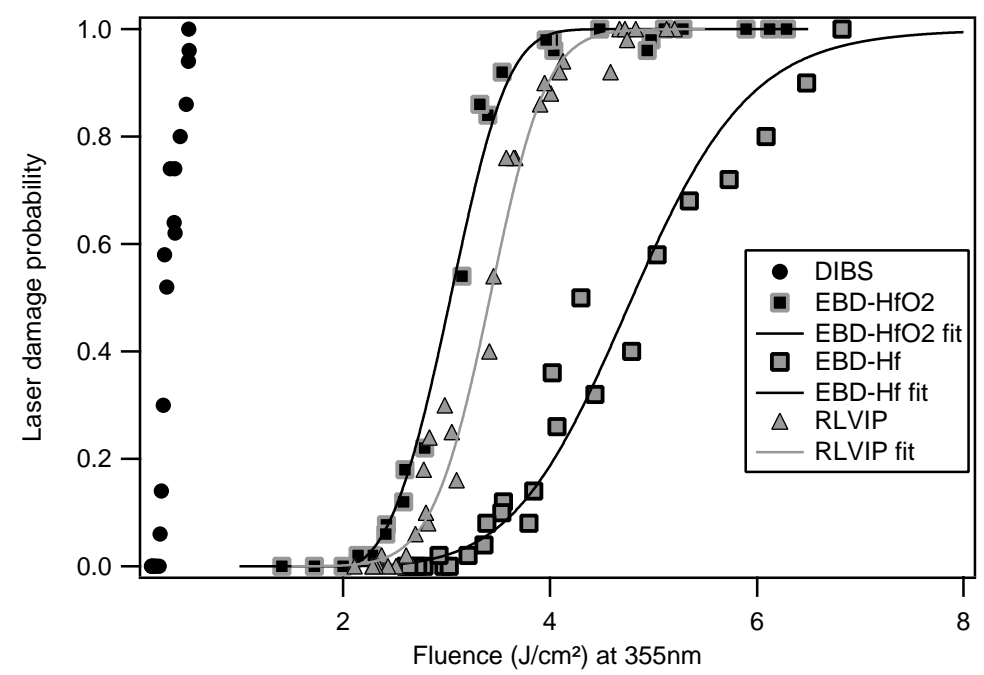

Figure 4. Laser damage probability curves measured at $355 \mathrm{~nm}$ for the different hafnia samples

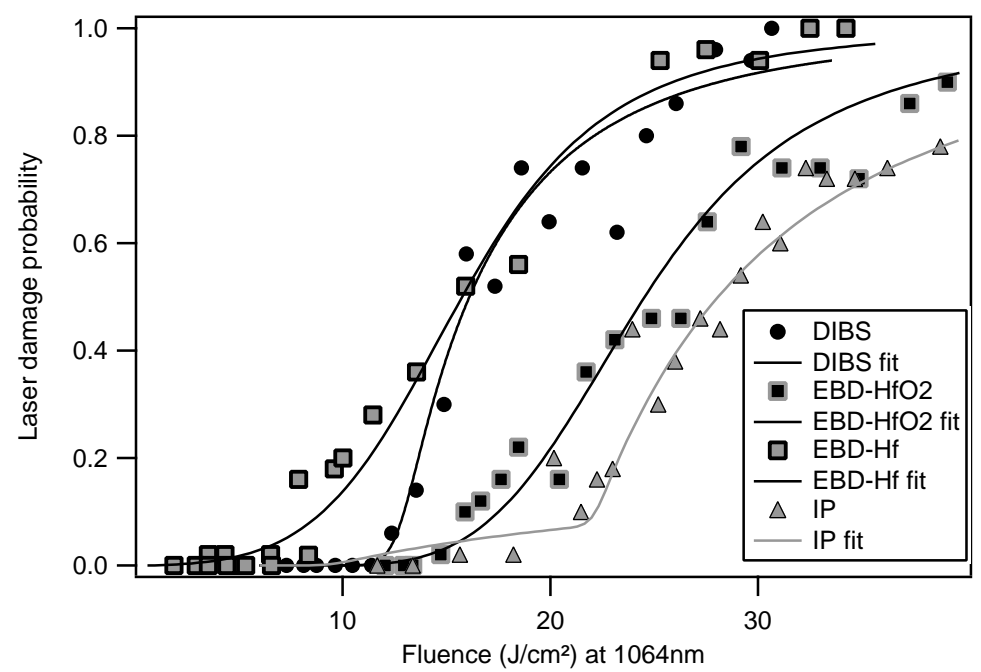

Figure 5. Laser damage probability curves measured at $1064 \mathrm{~nm}$ for the different hafnia samples

The LIDT of the films, i.e. highest fluence where no damage is observed, are the following :

- EBD- $\mathrm{HfO}_{2}: 2.1 \mathrm{~J} / \mathrm{cm}^{2}$ at $355 \mathrm{~nm}$ and $14.5 \mathrm{~J} / \mathrm{cm}^{2}$ at $1064 \mathrm{~nm}$

- EBD-Hf : $2.8 \mathrm{~J} / \mathrm{cm}^{2}$ at $355 \mathrm{~nm}$ and $3.5 \mathrm{~J} / \mathrm{cm}^{2}$ at $1064 \mathrm{~nm}$

- RLVIP : $2.3 \mathrm{~J} / \mathrm{cm}^{2}$ at $355 \mathrm{~nm}$ and $15.5 \mathrm{~J} / \mathrm{cm}^{2}$ at $1064 \mathrm{~nm}$ 
- DIBS : $0.22 \mathrm{~J} / \mathrm{cm}^{2}$ at $355 \mathrm{~nm}$ and $12 \mathrm{~J} / \mathrm{cm}^{2}$ at $1064 \mathrm{~nm}$

- Substrate : $18 \mathrm{~J} / \mathrm{cm}^{2}$ at $355 \mathrm{~nm}$ and $70 \mathrm{~J} / \mathrm{cm}^{2}$ at $1064 \mathrm{~nm}$

The best threshold in the IR is found for the RLVIP technique and the worst result is obtained for EBD-Hf. This is quite surprising compared to general results in this field where EBD-Hf is found to be the best technology, particularly at $1064 \mathrm{~nm}$. This indicate that the deposition parameters chosen are far from optimal for the EBD-Hf process and can be further optimized for $1064 \mathrm{~nm}$ applications (a high roughness is also found for this films). The results for the RLVIP coatings are interesting and promising since no data were published to our knowledge for this technique.

For the DIBS thin films tested at $355 \mathrm{~nm}$, a very low LIDT is found. This is associated to a high extinction coefficient and a damage morphology evidencing burning and melting of the film. In this case, damage is link to the high intrinsic absorption level of the film and thermal melting of the material is the main laser damage mechanism. This can be due to a stoechiometric problem of the film, such as oxygen deficiency, linked to the bombardment process or the relatively low substrate temperature compared to other technologies. The optimization of the DIBS process for UV applications seems delicate : no report of high LIDT DIBS films in the UV are published to our knowledge.

\section{CONCLUSION}

Single layer of $\mathrm{SiO}_{2}$ and $\mathrm{HfO}_{2}$ have been deposited on fused silica substrates with different state of the art assisted and non-assisted deposition techniques. The coatings have been laser-damage tested at 355 and $1064 \mathrm{~nm}(12 \mathrm{~ns})$. The LIDT were found to be strongly dependent on the deposition technique but also on the test wavelength : no correlation were found between LIDT at 355 and 1064nm. High laser damage threshold were found for dense coatings. This results appear promising for the production of laser damage resistant multilayer coatings.

\section{REFERENCES}

1. M.R. Kozlowski, In F. Flory (Ed), Thin Films for Optical Systems, Marcel Dekker (1995) 521-549.

2. E. Hacker, H. Lauth and P. Weibrodt, Proc. SPIE 2714 (1996) 317.

3. C.J. Stolz and F. Génin, In N. Kaiser and H. Pulker (Eds), Optical Interference Coatings, Springer (2003) 309-333.

4. R. Chow, S. Falabella, G.E. Loomis, F. Rainer, C.J. Stolz, 'Reactive evaporation of low defect density hafnia', Applied optics 32, 5567-5574 (1993)

5. C.J. Stolz, L.M. Sheehan, M.K. Gunten, R.P. Bevis and D. Smith, 'the advantages of evaporation of hafnium in a reactive environment to manufacture high damage threshold multilayer coatings by electron-beam deposition'. In C. Amra, H.A. Macleod (eds), Advances in Optical Interference Coatings. 3338 (1999) 218-324.

6. M. Alvisi, M. Di Giulio, S.G. Marrone, M.R. Perrone, M.L. Protopapa, A. Valentini, L. Vasanelli, 'HfO ${ }_{2}$ films with high laser damage threshold', Thin Solid Films 410 (2002) 86-93.

7. P. André, L. Poupinet, G. Ravel, 'Evaporation and ion assisted deposition of $\mathrm{HfO}_{2}$ coatings : Some keypoints for high power applications', J. Vac. Sci. Technol. 18 (2000) 2372-2377.

8. R. Thielsch, A. Gatto, J. Heber, N. Kaiser, 'A comparative study of the UV optical and structural properties of $\mathrm{SiO}_{2}, \mathrm{Al}_{2} \mathrm{O}_{3}$, and $\mathrm{HfO}_{2}$ single layers deposited by reactive evaporation, ion-assisted deposition and plasma ion-assisted deposition', Thin Solid Films 410 (2002) 86-93.

9. L. Gallais, H. Krol, J.Y. Natoli, M. Commandré, M. Cathelinaud, L. Roussel, M. Lequime, C. Amra, 'Laser damage resistance of silica thin films deposited by Electron Beam Deposition, Ion Assisted Deposition, Reactive Low Voltage Ion Plating and Dual Ion Beam Sputtering', Thin Solid Films 515 (2007) 3830-3836.

10. L. Gallais, J. Capoulade, J.Y. Natoli, M. Commandré, M. Cathelinaud, C. Hoc, M. Lequime, 'Laser damage resistance of Hafnia thin films deposited by Electron Beam Deposition, Reactive Low Voltage Ion Plating and Dual Ion Beam Sputtering', Applied Optics, 47 (2008).

11. D. Milam, W. H. Lowdermilk, F. Rainer, J. E. Swain, C. K. Carniglia, T. Tuttle Hart, "Influence of deposition parameters on laser-damage threshold of silica-tantala AR coatings," Applied optics 21, 3689-3694 (1982) 
12. H. Krol, L. Gallais, M. Commandré, C. Grézes-Besset, D. Torricini, G. Lagier, "Influence of polishing and cleaning on the laser-induced damage threshold of substrates and coatings at $1064 \mathrm{~nm}$," Optical Engineering 46, $023402(2007)$

13. ISO standard 11254-1, 'Determination of laser-damage threshold of otpical surfaces-Part 1: 1-on-1 test', 2000

14. H. Krol, L. Gallais, C. Grèzes-Besset, J.Y. Natoli and M. Commandré, Optics Communications 256 (2005) 184.

15. M. Alvisi, G. De Nunzio, M. Di Giulio, M.C. Ferrara, M.R. Perrone, L. Protopapa and L. Vasanelli, Applied Optics 38 (1999) 1237.

16. J. Dijon, B. Rafin, C. Pell, J. Hue, G. Ravel and B. André, Proc. SPIE 3902 (1999) 158. 


\section{Laser damage of silica and hafnia thin films made by different deposition technologies [6720-30]}

Q I saw in your chart the deposition rate for the ion beam is $.05 \mathrm{~nm}$ per second. This rate would mean one hour or two for deposition, correct?

A It depends on the number of layers.

Q Ion beam deposition is obviously a practical technique, but you were your rates realistic at it being so slow?

A Yes, it was very slow, but if you want a high density threshold, it will be a problem.

Q You did some computations of absorption, by the hafnium metallic particles and I wondered what kind of dielectric functions you used?

A Yes, hafnium. The reference values for the reference for hafnium which is made up of metallic crystals were used.

Q What I saw there was data for two sizes of metallic clusters, but not for continuously changing sizes. Did you do some extrapolations?

A We have taken data for the big sizes. It's not the defects sizes of one nanometer between the damage sites, but or a large difference. 